\title{
Protein Profiling of Escherichia coli on exposure to imidacloprid
}

\author{
A. A. Shetti ${ }^{1}$, B. B. Kaliwal ${ }^{2} *$ \\ ${ }^{I}$ Dept of Biotechnology and Microbiology Karnatak University, Dharwad \\ ${ }^{2}$ Department of Biotechnology Davangere University, Davangere \\ Corresponding authors: Dr. B. B. Kaliwal
}

\begin{abstract}
Imidacloprid has gained great attention as a synthetic insecticide that acts in a similar manner as nicotine and is now widely used for the control of pests. Bacteria react to environmental or chemical stress by synthesizing specific sets of proteins and these can be analyzed by protein profiling using SDS PAGE. The present investigation was undertaken to reveal protein profile changes and differentially expressed proteins in soil isolate Escherichia coli on dose and durational exposure to imidacloprid. Protein profiling of Escherichia coli treated with different $\left(10^{-7}\right.$ to $\left.10^{-3} \mathrm{M}\right)$ concentrations of imidacloprid observed regularly at the duration of 24 hrs for a period of 96 hours, showed the over expressions of certain protein, expression of stress proteins and novel proteins. The proteins expressed were observed to be dose and durational dependent. The present investigation proves that imidacloprid exposure induces the expression of stress and novel proteins in soil isolate Escherichia coli. The expression of these proteins may be necessary for the protection of the Escherichia coli from toxic effects of imidacloprid. The specific protein profiles that are expressed in response to the stress induced by imidacloprid can be used to monitor the environmental samples for the presence of similar pollutants.
\end{abstract}

Keywords: Imidacloprid, Escherichia coli, Stress Proteins, protein profiles.

\section{Introduction}

Millions of tons of pesticides are applied annually; however, less than 5\% of these products are estimated to reach the target organism, with the remainder being deposited on the soil and nontarget organisms, as well as moving into the atmosphere and water [1].The polyacrylamide gel electrophoresis is fundamentally designed to detect protein molecules also extensively used as a detection and identification tool for viruses and bacteria in different environments. Microorganisms respond to environmental or chemical stress by synthesizing specific sets of proteins that can be analyzed by protein profiling using SDS PAGE. The systematic analysis of the proteins of different microorganisms have been already reported using SDS-PAGE to investigate the following in vivo processes and their regulation, protein regulation, protein stability, indirect effects of mutations, protein processing and message lifetimes [2]. This technique is being extensively used to determine in vivo amount of protein, its rate of synthesis, and its rate of degradation. Proteomics is the investigation of the protein content or the protein complement of the genome of a biological system, also termed the proteome [3]. The objective of proteome research is to identify and describe the complex responses of a biological system to different stimuli and detect all proteins and their functional responses to a stimulus [4]. Proteomic investigations of microbial communities in the natural environments not only provide the most realistic information about their function but also pose the greatest experimental and bioinformatics challenges [5]. One can determine protein expression profiles related to research for both microbial isolates and communities using this technique.

Many species of microorganisms are capable of not only surviving, but thriving in conditions previously thought to be inhabitable, tolerating desiccation, high temperatures, extreme $\mathrm{pH}$, high salinity and pesticides illustrating their capacity to acclimate to extreme environments [6]. The majorities of proteomic investigations of environmental microorganisms focus on model microorganisms cultured in the laboratory because of their ability to tolerate, degrades, or precipitate toxic compounds. These characters make these microorganisms attractive for environmental biotechnology applications, and proteomics can provide a better understanding of their functions in specific habitats [7]. Imidacloprid is a neurotoxic insecticide, which belongs to the class of the neonicotinoid pesticides and is now widely used for the control of pests. Imidacloprid is an agonist of the nicotinic acetylcholine receptor $(\mathrm{nAChR})$ at the neuronal and neuromuscular junctions in insects and vertebrates. The toxicity of imidacloprid is largely due to interference of the neurotransmission in the nicotinic cholinergic nervous system. Imidacloprid is a potential ground and surface water contaminant [8]. Therefore, the present investigation was undertaken to elucidate protein profile changes and differentially expressed proteins in soil isolate Escherichia coli on dose and durational exposure to imidacloprid. 


\section{Materials And Method}

\subsection{PREPARATION OF STOCK SOLUTION OF IMIDACLOPRID}

The sample of imidacloprid (confidor $®$ ) used in the experiment was supplied by Byers India Pvt. Ltd. The stock solution of $1 \mathrm{M}$ of imidacloprid was prepared and further diluted to give $10^{-3}$ to $10^{-7}$ required molar concentrations.

\subsection{MAINTENANCE AND PROPAGATION OF CULTURE}

The soil isolate Escherichia coli was maintained at $4^{\circ} \mathrm{C}$ on nutrient agar and sub cultured very fortnight. The medium used for toxicity testing was a optimized medium containing dextrose $-0.65 \mathrm{~g} \mathrm{l}$, Yeast extract - $1.05 \mathrm{~g} / \mathrm{l}, \mathrm{KHPO}-0.30 \mathrm{~g} / \mathrm{l}$, and $\mathrm{NaCl}-0.25 \mathrm{~g} / \mathrm{l}$ and $\mathrm{pH}(7.0-7.2)$.

\subsection{EXPERIMENTAL PROCEDURES}

The pre-inoculum (5ml) was inoculated to $250 \mathrm{ml}$ Erlenmeyer's flask containing $100 \mathrm{ml}$ of sterilized optimized medium amended with different molar concentrations of imidacloprid. The flasks were incubated at $37^{\circ} \mathrm{C}$ for 96 hours under shaking conditions at $120 \mathrm{rpm}$ on a rotary shaker and at regular intervals sample was taken out from each flask aseptically for analysis.

\subsubsection{ISOLATION OF PROTEIN}

The bacterial cell pellet was dissolved in $100 \mu$ l of lysis buffer and incubated at $37^{\circ} \mathrm{C}$ for $15 \mathrm{~min}$. the tubes were centrifuged and the supernatant was used as protein sample. These protein samples were analyzed by PAGE according to [9]. Marker proteins were used bearing molecular weight of 97, 66, 44, 29 and $14 \mathrm{kDa}$.

\subsection{Isolation and identification of soil isolate}

\section{Result}

The imidacloprid tolerant strain isolated during field studies for imidacloprid toxicity to soil bacteria were grown in nutrient broth containing $10^{-3}$ molar imidacloprid and incubated for seven days and plated on medium containing $10^{-3}$ molar imidacloprid single colony was isolated and named as SP-02. The isolated strain was a rod-shaped, gram negative, bacterium. By sequencing the 16S rRNA gene and comparing them with previously published 16S rRNA gene sequences, the strain was classified as a member of the genus Escherichia. Based on nucleotide homology and phylogenetic analysis (fig. 1), the culture SP-02 was identified as Escherichia coli strain SCDC-1 (GenBank Accession Number: HM576813.1) (Shetti and Kaliwal, 2012).

\subsection{Protein profiling of Escherichia coli induced by imidacloprid}

The present investigation was attempted to elucidate the protein profiling in Escherichia coli cells that were exposed to different concentrations of imidacloprid ranging from $10^{-7} \mathrm{M}$ to $10^{-3} \mathrm{M}$ for a period of $96 \mathrm{hrs}$, at regular intervals of $24 \mathrm{hrs}$, the proteins induced were analyzed. The protein expression was observed at 25, 40, $48,53,56,60,66,74$ and $76 \mathrm{kDa}$ at $24 \mathrm{hrs}$ (Fig. 1). On exposure to imidacloprid for $48 \mathrm{hrs}$ the bands were observed at 14, 18, 44, 53, 60, 80 and $90 \mathrm{kDa}$ (Fig. 2). The imidacloprid treated for $72 \mathrm{hrs}$ showed expression at $14,37,51,54,60,62,75$ and $81 \mathrm{kDa}$ (Fig. 3) and for $96 \mathrm{hrs}$ the expressions was observed at 14, 25, 35, 38, 44 and $60 \mathrm{kDa}$ (Fig. 4) respectively.

\section{Discussion}

Various insecticides to protect crops against insects have been used over the last 40 years. Most insecticides were applied by spraying in large quantities, thus inducing pollution of air, soils and waters. The use of pesticides has become an integral part of the modern agricultural system. It is estimated that 4 million tons of pesticides are applied to world crops annually for pest control [10]. The residual pesticides may become the contamination sources and pose a serious threat to the soil and groundwater environment through the rainfall infiltration process. Some pesticides act on biochemical processes that are common to many animals, plants and microorganisms, and thus are a greater hazard to non-target organisms [11].

The present investigation was attempted to elucidate the protein profiling in Escherichia coli that were exposed to different concentrations of imidacloprid ranging from $10^{-7} \mathrm{M}$ to $10^{-3} \mathrm{M}$ for a period of $96 \mathrm{hrs}$. Protein profile of Escherichia coli exposed to imidacloprid showed synthesis of commonly expressed protein, uniquely expressed, different stress proteins and over expression of some of the proteins. Different stress conditions induce expression of specific set of bacterial genes and several functions are repressed. Bacterial responses to different stress conditions studied mostly under in vitro provided useful information on survival under stress conditions and expression of different genes [12]. In study protein profiles of E. coli and Pseudomonas aeruginosa revealed expression stress response proteins on treatment with different doses of methomyl for four days [16]. On exposure to 2-chlorophenol, Pseudomonas putida KT2442 demonstrated different protein expression pattern where some of these proteins might play a major role in the stability of the cell under stress 
[13]. Exposure to the pesticides results in a qualitative and quantitative regulation of individual proteins in the cultures. It was observed that the proteins were expressed at different dose and duration of exposure and the intensity of the protein expressed increased with the dose of exposure of imidacloprid, indicating that the protein expressed is dose and durational dependant and imidacloprid induced stress.

Living organisms, especially micro-organisms, are exposed to various types of natural stresses, such as nutrient limitation, pesticides, pollution, drought, salinity, temperature, $\mathrm{pH}$, light intensity and quality, etc [14]. A molecular technique that has proved to be useful in typing bacterial strains is sodium dodecyl sulphate polyacrylamide gel electrophoresis (SDS-PAGE) of whole cell bacterial proteins, wherein differences seen in protein bands in different circumstances have been successfully used to group tolerant bacteria [15].

The present investigation was attempted to elucidate the protein profiling in Escherichia coli, that was exposed to different concentrations of imidacloprid ranging from $10^{-7} \mathrm{M}$ to $10^{-3} \mathrm{M}$ for a period of $96 \mathrm{hrs}$. Protein profile of Escherichia coli exposed to imidacloprid showed synthesis of commonly expressed protein, uniquely expressed, different stress proteins and over expression of some of the proteins. Different stress conditions induce expression of specific set of bacterial genes and several functions are repressed. Bacterial responses to different stress conditions studied mostly under in vitro provided useful information on survival under stress conditions and expression of different genes [12]. It was observed that the proteins were expressed at different dose and duration of exposure and the intensity of the protein expressed increased with the dose of exposure of imidacloprid, indicating that the protein expressed is dose and durational dependant and imidacloprid induced stress [16]. Asghar et al., (2006) made the similar observations, he analyzed the stress proteins of Escherichia coli induced in response to the pesticides cypermethrin, zeta-cypermethrin, carbofuran and bifenthrin.

Stress proteins are produced in Escherichia coli on exposure to pesticides to combat these harmful effects some of the proteins were induced by more than one pesticide [17]. It has been suggested that, the major protein modification is caused due to stress are the loss of amino acid modification, catalytic activity, carbonyl group formation, decrease in thermal stability, increase in acidity, change in fragmentation, viscosity, fluorescence, formation of protein protein crosslink's, s-s bridges and increased susceptibility to proteolysis. Further, other studies revealed that heavily oxidized proteins, extensively cross-linked and aggregated, are not only poor substrates for degradation but can also inhibit proteases to degrade other oxidized proteins [18] [ 19].

Several pesticides cause ROS interferes with protein biosynthesis due to formation of adduct with DNA, RNA and proteins [20]. The secretion of extra cellular proteins, including toxins and cellular effectors, is one of the key contributing factors in a bacterium's ability to thrive in diverse environments conditions. The expression of stress proteins observed in the present study may be due to the fact that microbial cells respond to environmental or chemical stress by inducing specific sets of proteins characteristic to each stress [21]. The proteins expressed might play a major role in the stability of the cell under stress [13].

Treatment with pesticide induces stress in the bacteria that can lead to four basic differences in terms of protein content; 1 . Production of some new proteins not present in the untreated cultures; 2 . Inhibition of some proteins that are produced by the untreated cultures; 3 . Increase in the level of expression of some proteins; 4. Decrease in the level of expression of some proteins that are present in the untreated cultures [22]. All four differences are directly associated with the response of different bacterial species under study to imidacloprid induced stress conditions. Our results tend to agree with researchers who reported that the production of novel proteins or the increased production of already existing proteins, which are only produced under stress conditions due to stress response in bacteria and other organisms [23]. Such uniquely expressed proteins observed in the present study may be due to increased longevity, cell division rate and survival when exposed to stress [24], selective degradation of the modified proteins [25], the proteins induced for cross protection in bacterial cells and inaccuracy during protein biosynthesis, chemical or physical damage [26], major difference in the regulatory pathways controlling the expression of starvation and different stress proteins[ 27].

Proteomic and metabolomic techniques can also be used to predict toxic potential of unknown chemicals by comparing specific patterns of protein and gene expression, reflecting the mode of action of unknown chemical, with the expression profiles of known toxicants. To conclude, ecotoxicogenomic approach seems promising for studying the effect of pollutants at low, environmentally relevant concentrations and long term exposure assessment of organisms [28].

The present investigation undertaken to elucidate protein profile changes and differentially expressed proteins in soil isolates Escherichia coli on dose and durational exposure to imidacloprid revealed expression of commonly expressed protein, uniquely expressed and over expression of some of the proteins in soil isolate. The different proteins expressed soil isolate Escherichia coli may be due to the bacterium's ability to thrive in diverse environments by production of novel proteins or the increased production of already existing proteins, which are only produced under stress conditions due to stress response in bacteria and other organisms [23]. The study shows that imidacloprid induced intoxication results in differential protein expression in soil isolate Escherichia coli. 


\section{Conclusion}

Present investigation revealed that imidacloprid exposure results in the expression of stress and novel proteins in soil isolate Escherichia coli. The expressed proteins may be necessary for the protection of the cell from toxic effects of imidacloprid. These specific protein profiles that are expressed in the present study may be used to monitor the environmental samples for the presence of imidacloprid and similar pollutants in the environment.

\section{References}

[1] Pimental D, Levitan L. Pesticides: amounts applied and amounts reaching pests. Biosciences. 1986; 36: 86-91

[2] Nakayama M, Ishizawa K, Nakajima J, Kawamura A, Umino T. Cellular protein profile of Halophilic archaea, Halobacterium halobium. Mem. Osaka Kyoiku Univ. Ser. La. 1996 ; 45: 81-91.

[3] Wilkins MR, Sanchez JC, Gooley A.A, Appel R.D, Humphery-Smith I, Hochstrasser DF, Williams KL. Progress with proteome projects: why all proteins expressed by a genome should be identified and how to do it. Biotechnol Genet Eng Rev. 1996;13: 19-50.

[4] Bell DY, Hook GE. Pulmonary alveolar proteinosis: analysis of airway and alveolar proteins. Am Rev Respir Dis, 1979; 119: 979990 .

[5] Valenzuela AS, Ben-Omar N, Abriouel H, Lopez RL, Ortega E, Canamero MM, Galvez A. Risk factors in Enterococci isolated from foods in Morocco: determination of antimicrobial resistance and incidence of virulence traits. Food Chem. Toxicol. 2008; 46: $2648-2652$.

[6] Stal L. Cyanobacteria: Diversity and versatility. Clues to life in Extreme Environments in Algae and cyanobacteria in extreme environments. 2007; 659-680.

[7] Lacerda CM, Reardo KF. Environmentalproteomics:applications of proteomic profiling in enivironmental microbiology and biotechnology. brief. funct. grnomics proteomic. 2009; 8: 75-87.

[8] Scholz K, Spiteller M. Influence of groundcover on the degradation of 14C-imidacloprid in soil. Brighton Crop Protection Conference - Pests and Diseases, 1992;883-888.

[9] Laemmli UK. Cleavage of structural proteins during the assembly of the head of bacteriophage T4. Nature. 1970; 227: 680-685.

[10] Pimentel D. Effects of pesticides on the environment. 10 Intl. Congress on Plant Protection. Crydo. 1983;2: 685-691.

[11] Moorman TB. A Review of Pesticide Effects on Microorganisms and Microbial Processes Related to Soil Fertility. Journal of Environmental Science and Health, 1989;2 (1):14-23.

[12] Chowdhury R, Sahu GK, Das J. () Stress response in pathogenic bacteria. J. Biosci. 1996;21: 149-160.

[13] Claudio G, Colangelo T, Anthony C. Two-dimensional gel electrophoresis analysis of the response of Pseudomonas putida KT2442 to 2- chlorophenol. Applied and Environmental Microbiology. 1995;61 (8): 2863-2872.

[14] Herrero OA, Muro-Pastor AM, Flores E. Nitrogen controlling cyanobacteria. J. Bacteriol. 2001;183: 411-425.

[15] Krech T, De Chastonay J, Falsen E. Epidemiology of diptheria:polypeptide and restriction enzyme analysis in comparison with conventional phage typing. Eur. J. Cli. Microbiol. Infect. Dis. 1988;7: 232-237.

[16] Shetti AA, Kaliwal BB. Imidacloprid induced intoxication in soil isolate Brevundimonas Sp. MJ 15. IJLPR. 2012;2( 3): 105-117.

[17] Asghar MN, Ashfaq M, Ahmad Z, Khan IU. 2- D PAGE analysis of pesticide induced stress proteins of E. coli. Anal Bioanal Chem, 2006; 384:946-950.

[18] Dean RT, Fu S, Stocker R, Davies MJ. Biochemistry and pathology of radical-mediated protein oxidation. Biochem J. 1997; 324 : $1-18$.

[19] Grune T, Reinheckel T, Davies KJA. Degradation of oxidized proteins in mammalian cells. FASEB J. 1997:11, 526-534

[20] Doreswamy K, Shrilatha B, Rajeshkumar T, Muralidhara M. Nickel induced oxidative stress in testes of mice: evidence of DNA damage and genotoxic effects. Asian J Androl. 2004;25: 996-1003.

[21] Durrani R, Abubakar M, Javed Arshed M., Saleha S, Ullah, I, Ali Q. Biological characterization and protein profiles of two model bacteria by SDS-PAGE and FT-IR. ARPN Journal of Agricultural and Biological Science. 2008; 3: 6-16.

[22] Kumar N, Kumar R N, Bora A, Kaur AL. An Evaluation of Pesticide Stress Induced Proteins in three Cyanobacterial SpeciesAnabaena Fertilissima, Aulosira Fertilissima and Westiellopsis Prolifica using SDS-PAGE. International Journal of Biological and Medical Sciences.2011;1(1): 135-38.

[23] Rajendran UM, Elango K, Anand N. Effects of a fungicide, an insecticide and a biopesticide on tolypothrix scytonemoides. Pest. Biochem. Physiol. 2007;87: 164-171.

[24] Smith SJ, Barbee AS. Exercise stress response as an adaptive tolerance strategies in bacteria. Environ Health Persp. 1998;106: 325-330.

[25] Lee SG, Yoon BD, Park YG, Oh HM. Isolation of a novel pentachlorophenol degrading bacterium, Pseudomonas sp. Bu 34. J. Appl. Microbiol. 1998;85: 1-8.

[26] Vasilyeva OV, Potapenko NA, Ovchinnikova TV. Limited proteolysis of Escherichia coli ATP-Dependent protease ion. vestnik Moskovskogo Universtiteta, Khimiya, 2000; $41-46$.

[27] Lambert NH, Abshire K, Blanmenhorn D, Slonczewski JL. proteins induced in Escherichia coli by benzoic acid. J. Bacteriol. 1997; 179: 7595-7599.

[28] Logar RM., Vodovnik M. The applications of microbes in environmental monitoring Communicating Current Research and Educational Topics and Trends in Applied Microbiology, Méndez- Vilas (Ed.). New York. 2007 


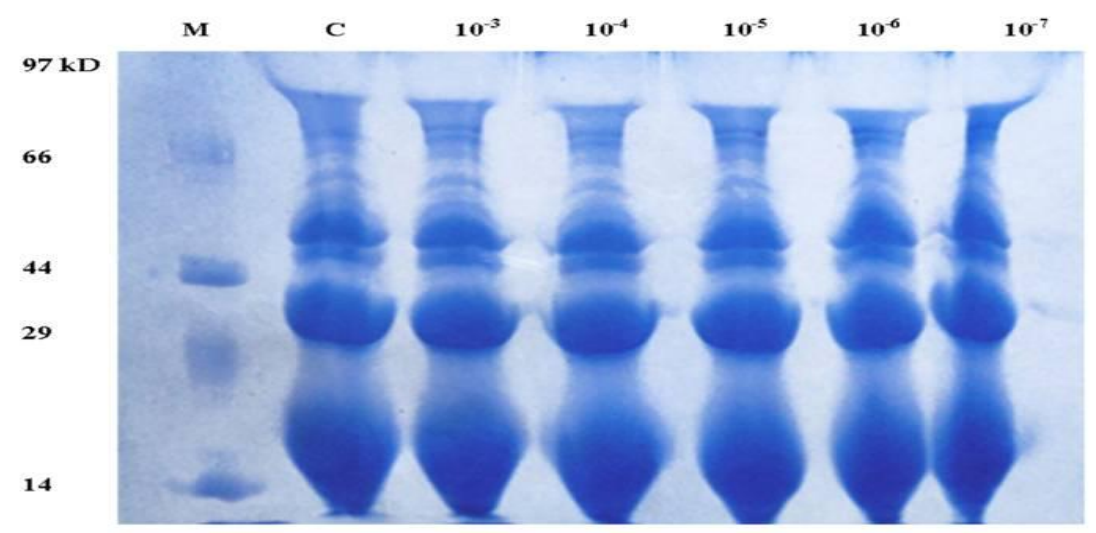

Fig. 1 Protein profiling of Escherichia coli after 24 hours of exposure to imidacloprid

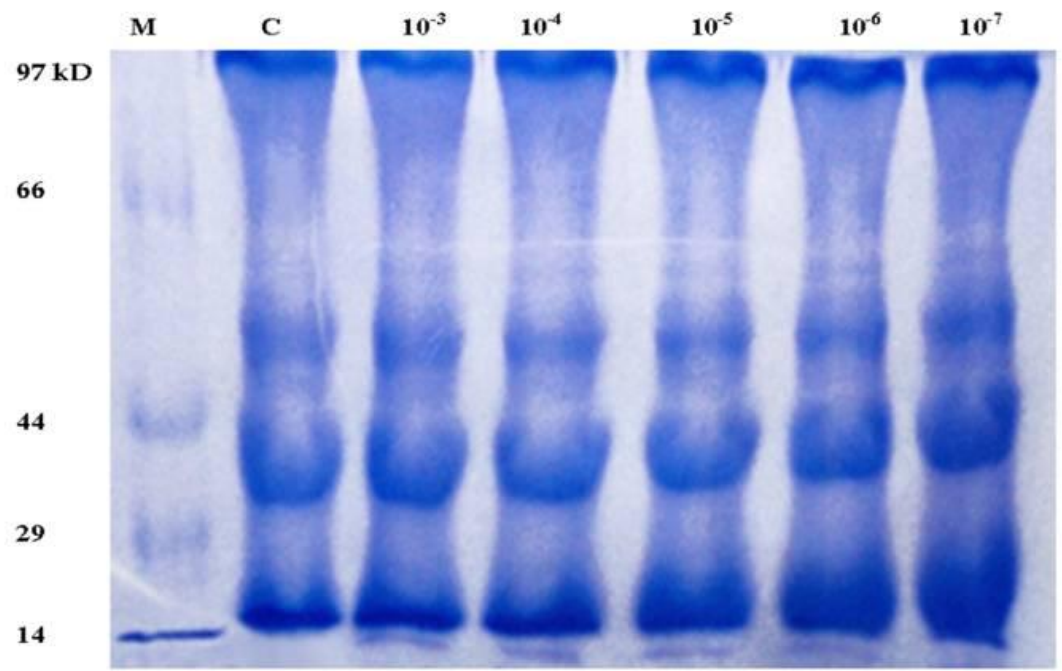

Fig. 2 Protein profiling of Escherichia coli after 48 hours of exposure to imidacloprid

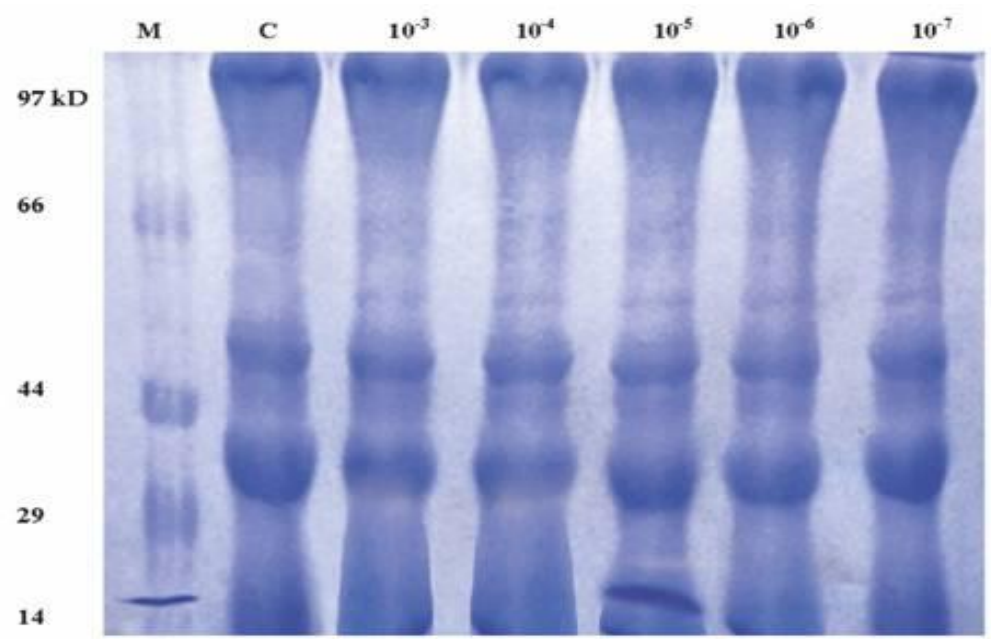

Fig. 3 Protein profiling of Escherichia coli after 72 hours of exposure to imidacloprid 


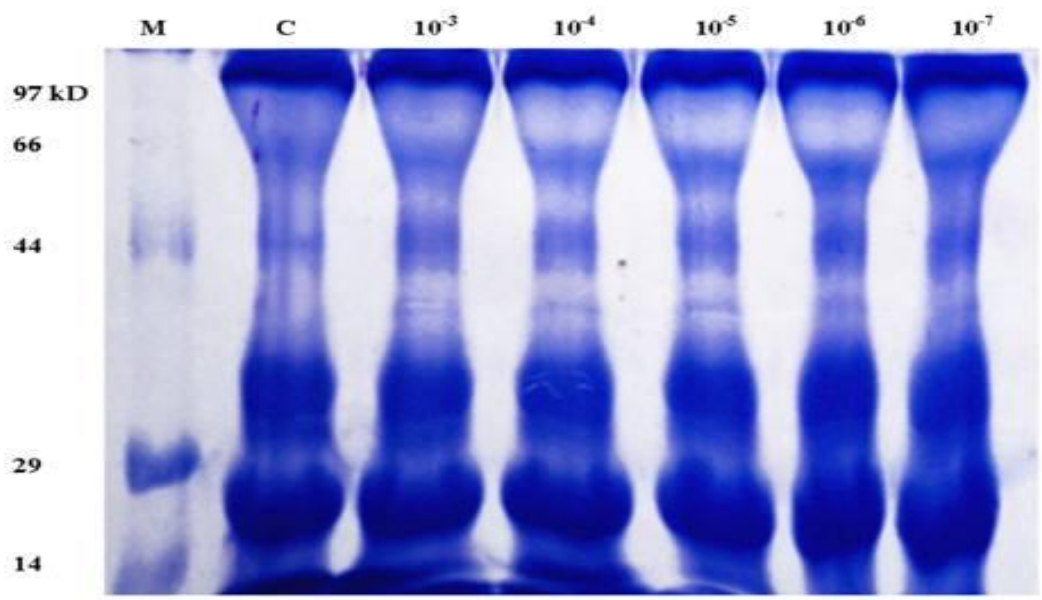

Fig. 4 Protein profiling of Escherichia coli after 96 hours of exposure to imidacloprid

IOSR Journal of Biotechnology and Biochemistry (IOSR-JBB) is UGC approved Journal with S1. No. 4033, Journal no. 44202.

A. A. Shetti. "Protein Profiling of Escherichia coli on exposure to imidacloprid." IOSR Journal of Biotechnology and Biochemistry (IOSR-JBB) 3.4 (2017): 42-47. 